\title{
THIRTEENTH ANNUAL LIST OF PAPERS
}

\author{
READ BEFORE THE AMERICAN MATHEMATICAL SOCIETY AND \\ SUBSEQUENTLY PUBLISHED, INCLUDING REFERENCES \\ TO THE PLACES OF THEIR PUBLICATION.
}

Ames, L. D. On the Theorem of Analysis Situs relating to the Division of the Plane or of Space by a Closed Curve or Surface. Read Dec. 29, 1903. Bulletin of the American Mathematical Society, vol. 10, No. 6, pp. 301-305; Mar., 1904.

BlichFeldt, H. F. On the Order of Linear Homogeneous Groups. Read (San Francisco) April 25, 1903. Transactions of the American Mathematical Society, vol. 4, No. 4, pp. 387-397; Oct., 1903.

BLIss, G. A. Jacobi's Criterion when both End-Points are Variable. Read Aug. 31, 1903. Mathematische Annalen, vol. 58, Nos. 1-2, pp. 70-80; Dec., 1903.

An Existence Theorem for a Differential Equation of the Second Order, with an Application to the Calculus of Variations. Read (Chicago) Dec. 31, 1903. Transactions of the American Mathematical Society, vol. 5, No. 2, pp. 113-125; Apr., 1904.

Brewster, Miss H. B. Collineations of Space which leave Invariant a Quadric Surface. Read Sept. 3, 1903. Kansas University Science Bulletin, vol. 1, No. 11, pp. 281-302; Nov., 1902.

Bromwich, T. J. I'A. Similar Conics through Three Points. Read Sept. 1, 1903. Transactions of the American Mathematical Society, vol. 4, No. 4, pp. 489-492; Oct., 1903.

Cole, F. N. On the Factoring of Large Numbers. Read Oct. 31, 1903. Bulletin of the American Mathematical Society, vol. 10, No. 3, pp. 134-137; Dec., 1903.

The Groups of Order $p^{3} q^{\beta}$. Read Feb. 27, 1904. Transactions of the American Mathematical Society, vol. 5, No. 2, pp. 214-219; Apr., 1904.

Collins, J. V. A General Notation for Vector Analysis. Read Sept. 2, 1902. American Mathematical Monthly, vol. 10, Nos. 6-7, pp. 161-163; June-July, 1903.

JuRTISs, D. R. On the Invariants of a Homogeneous Quadratic Differential Equation of the Second Order. Read Dec. 27, 1901. American Journal of Mathematics, vol. 25, No. 4, pp. 365-382; Oct., 1903.

Binary Families in a Triply Connected Region, with Especial Reference to Hypergeometric Families. Read Aug. 31, 1903. Memoirs of the American Academy of Arts and Sciences, vol. 13, No. 1, pp. 1-59; Jan., 1904.

Dickson, L. E. On the Subgroups of Order a Power of $p$ in the Quaternary Abelian Group in the Galois Field of order $p^{n}$. Read Aug. 31, 1903. Transactions of the American Mathematical Society, vol. 4, No. 4, pp. 371-386; Oct., 1903. 
On the Reducibility of Linear Groups. Read Aug. 31, 1903. Transactions of the American Mathematical Society, vol. 4, No. 4, pp. 434-436; Oct., 1903.

Two Systems of Subgroups of the Quaternary Abelian Group in a General Galois Field. Read Aug. 31, 1903. Bulletin of the American Mathematical Society, vol. 10, No. 4, pp. 178-184; Jan., 1904.

Determination of all Groups of Binary Linear Substitutions with Integral Coeflicients taken Modulo 3 and of Determinant Unity. Read Aug. 31, 1903. Annals of Mathematics, $2 d$ ser., vol. 5, No. 3, pp. 140-144; Apr., 1904.

Determination of all the Subgroups of the Known Simple Group of Order 25920. Read Aug. 31, 1903. Transactions of the American Mathematical Society, vol. 5, No. 2, pp. 126-166; Apr., 1904.

The Subgroups of Order a Power of 2 of the Simple Quinary Orthogonal Group in the Galois Field of Order $p^{n}=8 l \pm 3$. Read Aug. 31, 1903. Transactions of the American Mathematical Society, vol. 5, No. 1, pp. 1-38; Jan., 1904.

Fields whose Elements are Linear Differential Expressions. Read Apr. 25, 1903. Bulletin of the American Mathematical Society, vol. 10, No. 1, pp. 30-31; Oct., 1903.

A Generalization of Symmetric and Skew-Symmetric Determinants. Read (Chicago) Jan. 1, 1904. American Mathematical Monthly, vol. 10, No. 12, pp. 253-256; Dec., 1903.

On the Subgroups of the Order a power of $p$ in the Linear Homogeneous and Fractional Group in the $G F[p]$. Read Feb. 27, 1904. Bulletin of the American Mathematical Society, vol. 10, No. 8, pp. 385-397; May, 1904.

The Abstract Group Simply Isomorphic with the Group of Linear Fractional Transformations in a Galois Field. Read (San Francisco) Dec. 20, 1902. Proceedings of the London Mathematical Society, vol. 35, Nos. 809-813, pp. 292-305; July, 1903.

EIesland, J. On Nullsystems in Space of Five Dimensions and their Relation to Ordinary Space. Read Sept. 2, 1902. American Journal of Mathematics, vol. 26, No. 2, pp. 193-148; Apr., 1904.

EisenhaRT, L. P. Surfaces whose Lines of Curvature in One System are Represented on the Sphere by Great Circles. Read Apr. 26, 1902. American Journal of Mathematics, vol. 25, No. 4, pp. 349364 ; Oct., 1903.

Congruences of Curves. Read Feb. 28, 1903. Transactions of the American Mathematical Society, vol. 4, No. 4, pp. 470-488; Oct., 1903.

Congruences of Tangents to a Surface and Derived Congruences. Read Apr. 25, 1903. American Journal of Mathematics, vol. 26, No. 2, pp. 180-208; Apr., 1904.

Емсн, A. Note on the $p$-Discriminant of Ordinary Linear Differential Equations. Read Aug. 31, 1903. Bulletin of the American Mathematical Society, vol. 10, No. 3, pp. 137-138; Dec., 1903. University of Colorado Studies, vol. 1, No. 4, pp. 269-274; Feb., 1904. 
Epsteen, S. On Linear Differential Congruences. Read Apr. 25, 1903. Bulletin of the American Mathematical Society, vol. 10, No. 1, pp. 23-30; Oct., 1903.

On the Definition of Reducible Hypercomplex Number Systems. Read (Chicago) Jan. 1, 1904. Transactions of the American Mathematical Society, vol. 5, No. 1, pp. 105-109; Jan., 1904.

- Semireducible Hypercomplex Number Systems. Read Aug. 31, 1903. Transactions of the American Mathematical Society, vol. 4, No. 4, pp. 437-444; Oct., 1903.

On Linear Homogeneous Difference Equations and Continuous Groups. Read (Chicago) Apr. 2, 1904. Bulletin of the American Mathematical Society, vol. 10, No. 10, pp. 499-504; July, 1904.

Field, P. On the Forms of Unicursal Quintic Curves. Read Apr. 26, 1902. American Journal of Mathematics, vol. 26, No. 2, pp. 149163 ; Apr., 1904.

Fite, W. B. On some Properties of Groups whose Orders are Powers of a Prime. Read Feb. 22, 1902 and Dec. 28, 1903. Bulletin of the American Mathematical Society, vol. 10, No. 7, pp. 346-350; Apr., 1904.

GALE, A. S. On Three Types of Surfaces of the Third Order Regarded as Double Surfaces of Translation. Read Oct. 31, 1903. Bulletin of the American Mathematical Society, vol. 10, No. 4, pp. 188-191; Jan., 1904.

Goursat, E. A Simple Proof of a Theorem in the Calculus of Variations (Extract from a Letter to Mr. W. F. Osgood). Read Oct. 31, 1903. Transactions of the American Mathematical Society, vol. 5, No. 1, pp. 110-112; Jan., 1904.

Gundersen, C. On the Content or Measure of Assemblages of Points. Read Dec. 28, 1901. Doctor Dissertation, published by the Author, New York, 1901.

Haskell, Mr. W. Generalization of a Fundamental Theorem in the Geometry of the Triangle. Read (Chicago) Jan. 2, 1902. Archiv der Mathematik und Physik, ser. 3, vol. 5, Nos. 3-4, pp. 278-281; June, 1903.

Haskins, C. N. On the Invariants of Quadratic Differential Forms, II. Read Sept. 1, 1903. Transactions of the American Mathematical Society, vol. 5, No. 2, pp. 167-192; Apr., 1904.

HAwKES, H. E. Enumeration of Non-Quaternion Number Systems. Read Dec. 30, 1902. Mathematische Annalen, vol. 58, No. 3, pp. 361-379; Mar., 1904.

HuN, J. G. On Certain Invariants of two Triangles. Read Dec. 28, 1903. Transactions of the American Mathematical Society, vol. 5, No. 1, pp. 39-55; Jan., 1904.

Kasner, E. A Relation between the Circular and the Projective Transformations of the Plane. Read Feb. 28, 1903. Annals of Mathematics, ser. 2, vol. 5, No. 2, pp. 99-104; Jan., 1904. 
Isothermal Systems of Geodesics. Read Aug. 31, 1903. Transactions of the American Mathematical Society, vol. 5, No. 1, pp. 56-60; Jan., 1904.

The Riccati Differential Equations which Represent Isothermal Systems. Read Dec. 29, 1903. Bulletin of the American Mathematical Society, vol. 10, Nos. 7, 8, pp. 341-346, 405; Apr., May, 1904.

Determination of the Algebraic Curves whose Polar Conics are Parabolas. Read Dec. 28, 1901. American Journal of Mathematics, vol. 26, No. 2, pp. 164-168; Apr., 1904.

Kelloga, O. D. Note on Cauchy's Integral. Read Dec. 28, 1903. Bulletin of the American Mathematical Society, vol. 10, No. 5, pp. 255-257; Feb., 1904.

Кинг, H. W. On Imprimitive Substitution Groups. Read Feb. 24, June 27 and Oct. 27, 1900. American Journal of Mathematics, vol. 26, No. 1, pp. 45-102; Jan., 1904.

Laves, K. The Orbit of the Minor Planet (334). Read in part (Chicago) Mar. 29, 1902. Decennial Publications of the University of Chicago, vol. 8, pp. 401-413.

LoEwy, A. Zur Gruppentheorie mit Anwendungen auf die Theorie der linearen homogenen Differentialgleichungen, Read Aug. 31, 1903. Transactions of the American Mathematical Society, vol. 5, No. 1, pp. 61-80; Jan., 1904.

LovetT, E. O. Periodic Solutions of the Problem of Four Bodies. Read Sept. 1, 1903. Quarterly Journal of Mathematics, vol. 35, No. 2, pp. 116-155; Oct., 1903.

- Systems of Periplegmatic Orbits. Read Apr. 30, 1904. Astronomical Journal, vol. 24, No. 561, pp. 75-81; May, 1904.

Maschke, H. A Symbolic Treatment of the Theory of Invariants of Quadratic Differential Quantics of $n$ variables. Read (Chicago) Apr. 11, 1903. Transactions of the American Mathematical Society, vol. 4, No. 4, pp. 445-469; Oct., 1903.

Mason, C. M. Green's Theorem and Green's Functions for Certain Systems of Differential Equations. Read Sept. 1, 1903. Transactions of the American Mathematical Society, vol. 5, No. 2, pp. 220-225; Apr., 1904.

Merrill, Helen A. On Solutions of Differential Equations which Possess an Oscillation Theorem. Read Aug. 31, 1903. Transactions of the American Mathematical Society, vol. 4, No. 4, pp. 423433 ; Oct., 1903.

Miller, G. A. On the Generalization and Extension of Sylow's Theorem. Read (Chicago) Dec. 31, 1903. American Mathematical Monthly, vol. 11, No. 2, pp. 29-32; Feb., 1904.

- AND Moreno, H. C. Non-Abelian Groups in which every Subgroup is Abelian. Read (San Francisco) May 3, 1902 and April 25, 1903. Transactions of the American Mathematical Society, vol. 4, No. 4, pp. 398-404; Oct., 1903.

Moreno, H. C. See Mrller, G. A. 
Moritz, R. E. Generalization of the Differentiation Process. Read (Chicago) April 6, 1901. American Journal of Mathematics, vol. 24, No. 3, pp. 257-302; July, 1902.

Moulton, F. R. On Certain Rigorous Methods of treating Problems in Celestial Mechanics. Read (Chicago) April 6, 1901 and Sept. 2, 1902. Decennial Publications of the University of Chicago, vol. 8, pp. 119-142; 1902.

The True Radii of Convergence of the Expressions for the Ratios of the Triangles when Developed as Power Series in the Time Intervals. Read (Chicago) Apr. 11, 1903. Astronomical Journal, vol, 23, Nos. 537, 538, pp. 93-102; May, 1903.

Newson, H. B. On the Generation of Finite from Infinitesimal Transformations-a Correction. Read (Chicago) Jan. 2, 1903. Bulletin of the American Mathematical Society, vol. 10, No. 4, pp. 191193 ; Jan., 1904.

- A New Theory of Collineations and their Lie Groups. Read Aug. 25, 1899 and June 27, 1900. American Journal of Mathematics, vol. 24, No. 2, pp. 109-172; Apr., 1902.

OsGood, W. F. The Integral as the Limit of a Sum, and a Theorem of Duhamel's. Read Feb. 28, 1903. Annals of Mathematics, ser. 2, vol. 4, No. 4, pp. 161-178; July, 1903.

On a Gap in the Ordinary Presentation of Weierstrass's Theory of Functions. Read Dec. 28, 1903. Bulletin of the American Mathematical Society, vol. 10, No. 6, pp. 294-301; Mar., 1904.

Peirce, B. O. On Families of Curves which are the Lines of certain Plane Vectors, either Solenoidal or Lamellar. Read Apr. 25, 1903. Proceedings of the American Academy of Arts and Sciences, vol. 38, No. 24, pp. 661-678; May, 1903.

- On the Lines of Certain Classes of Solenoidal or Lamellar Vectors Symmetrical with Respect to an Axis. Read Aug. 31, $1903 . \quad$ Proceedings of the American Academy of Arts and Sciences, vol. 39, No. 12, pp. 295-304; Dec., 1903.

Penfield, S. L. The Stereographic Projection and its Possibilities from a Graphical Standpoint. Read Oct. 27, 1900. American Journal of Sciences and Arts, ser. 4, vol. 11, No. 1 (61), pp. 1-24; Jan., 1901; No. 2 (62), pp. 115-144; Feb., 1901.

QuINr, J. J. A Linkage for Describing the Conic Sections by Continuous Motion. Read (Chicago) Jan. 1, 1904. American Mathematical Monthly, vol. 11, No. 1, pp. 12-13; Jan., 1904.

RIETz, H. L. On Primitive Groups of Odd Order. Read Aug. 20, 1901 and Feb. 22, 1902. American Journal of Mathematics, vol. 26, No. 1, pp. 1-30; Jan., 1904.

RoE, E. D., JR. Note on a Partial Differential Equation of the First Order. Read Sept. 2, 1902. Annals of Mathematics, ser. 2, vol. 4, No. 3, pp. 104-106; Apr., 1903.

On the Coefficients in the Product of an Alternant and a Symmetric Function. Read Dec. 29, 1902. Transactions of the American Mathematical Socety, vol. 5, No. 2, pp. 193-213; Apr., 1904. 
Schotrenfels, IDA M. Note on the Necessary Condition that two Linear Homogeneous Differential Equations shall have Common Integrals. Read Oct. 31, 1903. American Mathematical Monthly, vol. 10, No. 12, pp. 257-259; Dec., 1903.

Shaw, J. B. On Nilpotent Algebras. Read (Chicago) Jan. 2, 1903. Transactions of the American Mathematical Society, vol. 4, No. 4, pp. 405-422; Oct., 1903.

Sisam, C. H. On Directrix Curves of Quintic Scrolls. Read Apr. 25, 1903. Bulletin of the American Mathematical Society, vol. 10, No. 1, pp. 32-34; Oct., 1903.

- On Self-Dual Scrolls. Read Apr. 30, 1904. Bulletin of the American Mathematical Slociety, vol. 10, No. 9, pp. 440-441; June, 1904.

Stocum, S. E. Rational Formulas for the Strength of a Concrete-Steel Beam. Read Sept. 1, 1903. Engineering News, vol. 50, No. 5, pp. 107-109; July, 1903.

Swift, E. On the Condition that a Point Transformation of the Plane be a Projective Transformation. Read Oct. 31, 1903, Bulletin of the American Mathematical Society, vol. 10, Nos. 5, 7, pp. 247-254. 361 ; Feb., Apr., 1904.

Westuund, J. On the Congruence $x \phi(P) \equiv 1$, mod. $P$. $\quad$ Read Aug. 31, 1903. Bulletin of the American Mathematical Society, vol. 10, No. 2, pp. 78-80; Nov., 1903.

White, H. S. Linear Systems of Curves upon Algebraic Surfaces (Abstract of Boston Colloquium Lectures). Delivered Sept. 2-5, 1903. Bulletin of the American Mathematical Society, vol. 10, No. 3, pp. 120-124; Dec., 1903.

Wintrtaker, E. T. An Expression of Certain Known Functions as Generalized Hypergeometric Functions. Read Aug. 31, 1903. Bulletin of the American Mathematical Society, vol. 10, No. 3, pp. 125-134; Dec., 1903.

Wilczynsiri, E. J. A Fundamental Theorem in the Theory of Ruled Surfaces. Read (San Francisco) Dec. 19, 1903. Mathematische Annalen, vol. 58, Nos. 1-2, pp. 249-256, Dec., 1903.

Studies in the General Theory of Ruled Surfaces. Read (San Francisco) Dec. 19, 1903. Transactions of the American Mathematical Society, vol. 5, No. 2, pp. 226-252; Apr., 1904.

Wilson, E. B. The So-Called Foundations of Geometry. Read Apr. 25, 1903. Archiv der Mathematik und Physik, ser. 3, vol. 6, No. 1-2, pp. 104-122, Aug., 1903.

- A Generalized Conception of Area: Applications to Collineations in the Plane. Read Aug. 31, 1903. Annals of Mathematics, ser. 2, vol. 5, No. 1, pp. 29-45; Oct., 1903.

- Projective and Metric Geometry. Read Dec. 29, 1903. Annals of Mathematics, ser. 2, vol. 5, No. 3, pp. 145-150; Apr., 1904.

Young, J. W. On the Group of Sign $(0,3 ; 2,4, \infty)$ and the Functions Belonging to it. Read Sept. 2 and Dec. 29, 1902. Transactions of the American Mathematical Society, vol. 5, No. 1, pp. 81-104; Jan., 1904. 
Young, W. H. On a Test for Non-Uniform Convergence. Read Aug. 31, 1903. Bulletin of the American Mathematical Society, vol. 10, No. 5, pp. 239-246; Feb., 1904.

Report of the Committee of the American Mathematical Society on Definitions of College Entrance Requirements in Mathematics. Presented Aug. 31, 1903. Bulletin of the American Mathematical Society, vol. 10, No. 2, pp. 74-77; Nov., 1903.

Report on the Requirements for the Master's Degree, by the Committee of the Chicago Section. Presented (Chicago) Jan. 1, 1904. Bulletin of the American Mathematical Society, vol. 10, No. 8, pp. 330385; May, 1904. 